\title{
Closure of a persistent esophagopleural fistula assisted by a novel endoscopic suturing system
}

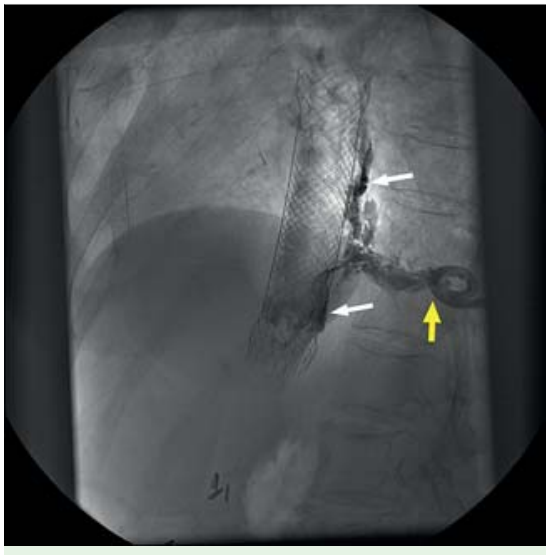

Fig. 1 Contrast examination depicting a 3-month esophagopleural fistula despite attempted closure with endoscopic clipping and stent placement. The chest drain (yellow arrow) was injected and fills a space around the esophagus, particularly in the region of the stent (white arrows), identifying a communication with the esophageal lumen. The clips found at the lower part of the image are from a previous cholecystectomy.

Gastrointestinal fistulas may be successfully managed endoscopically [1]. Novel endoscopic techniques for full thickness tissue approximation may serve as adjuvants for assisting fistula closure [2,3]; an example is a flexible endoscopic suturing system [4]. We describe a case of a chronic esophageal fistula, treated previously with endoscopic clipping and esophageal stenting, which was successfully managed using a novel endoscopic suturing system [5].

A 66-year-old woman presented with a 3-month history of a chronic esophagopleural fistula secondary to Boerhaave syndrome. The fistula was initially drained by thoracostomy and subsequently treated using endoscopic clipping followed by placement of a partially covered selfexpandable metal stent. Following removal of the stent 9 weeks later, a contrast esophagram revealed extravasation through a persistent esophagopleural fistulous opening $2 \mathrm{~cm}$ above the esophagogastric junction ( $\bullet$ Fig. 1 ). The fistula was $10 \mathrm{~mm}$ in diameter, with free flow of contrast through a long fistulous tract. Endoscopic closure of the fistula was performed using a novel endoscopic suturing device (Overstitch; Apollo Endosurgery,

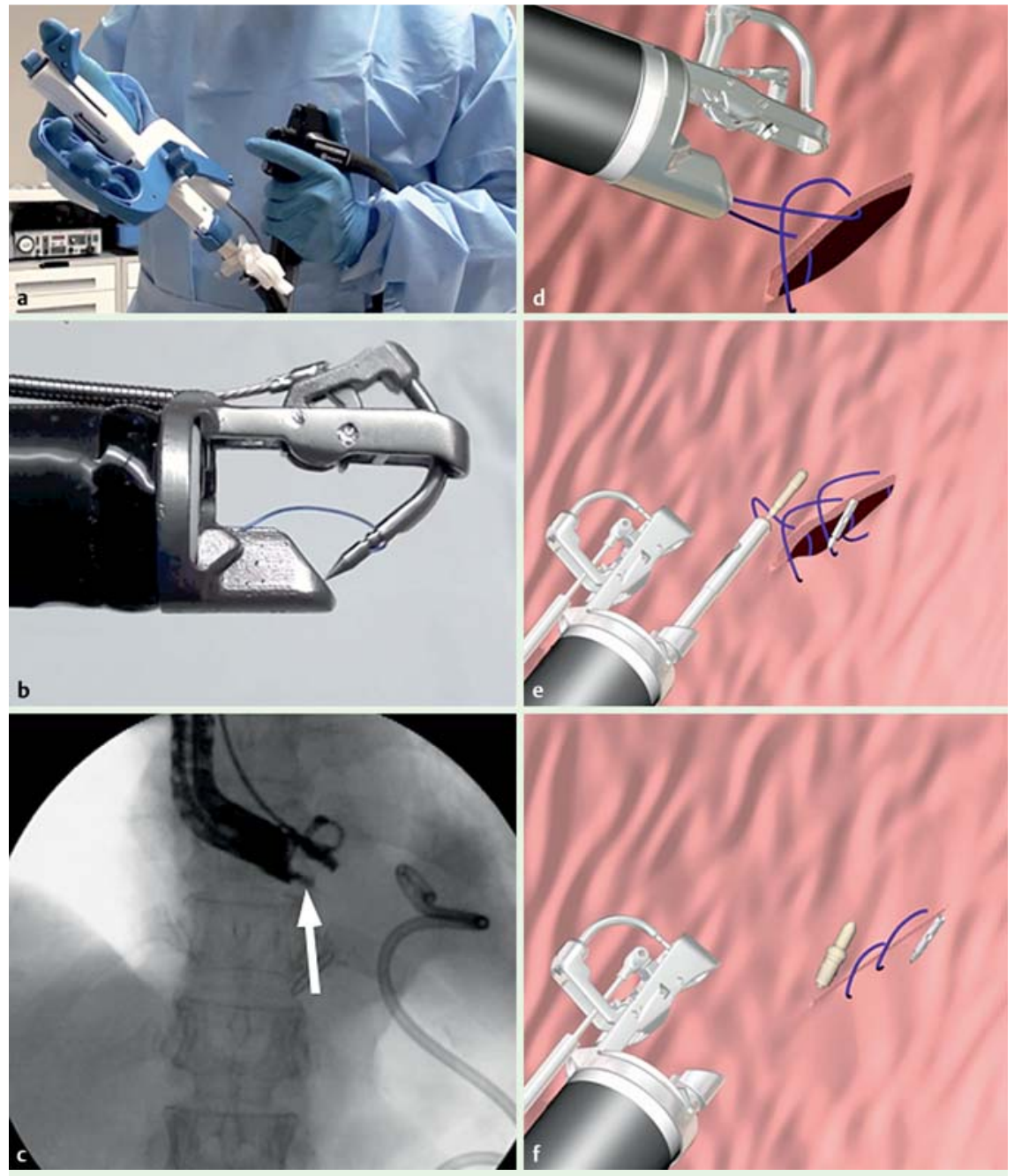

Fig. 2 Endoscopic suturing device schematics. a Device handle attached to the scope. b Detail of the pivoting curved-needle suturing mechanism (the needle has been attached half way to the suturing position). c Fluoroscopic image of the suturing device aiming at the fistula site. An endoscopic grasper is coming from the working channel (white arrow). $\mathbf{d}$ A running suture deployment. $\mathbf{e}$ The cinch mechanism: the needle has been detached from the needle holder, and the cinch is being advanced against the sutured wound. $\mathbf{f}$ The cinch has been deployed after adequate tightening.

Austin, Texas, USA) ( Fig. 2, Video 1 ) inserted through an esophageal overtube. A double-channel endoscope (Olympus GIF 2T160; Olympus, Center Valley, Pennsylvania, USA) fitted with the suturing device was advanced to the distal esophagus. Placement of a three-stitch running 3.0 polypropylene suture was successful at closing the fistula, and initial contrast instillation demonstrated no leak. Additionally, a partially covered stent was placed to cover the sutured defect. The stent was removed 4 weeks later, and a follow-up esophagogram showed a contrast leak, although the fistula was smaller ( $5 \mathrm{~mm})$, and the flow less extensive.

A second suturing procedure was planned to seal the remaining fistula opening (๑ Fig.3), starting with Argon plasma coagulation of the orifice of the fistula, followed by $10 \mathrm{~mL}$ human fibrin glue injection (Tisseel; Baxter, Westlake Village, California, USA). The fistula was closed again with three interrupted polypropylene 2.0 sutures using the suturing device in the same fashion as described 


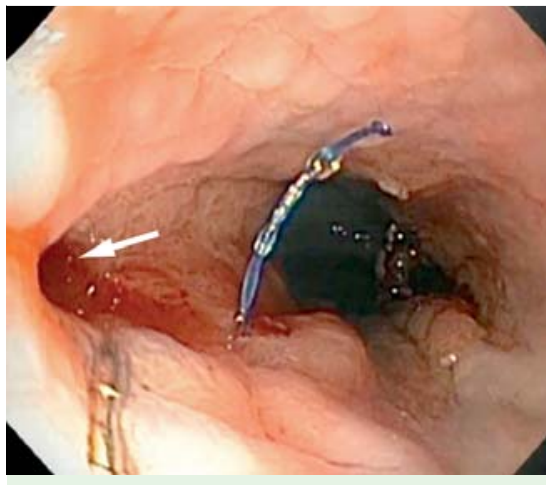

Fig. 3 Endoscopic view of the existing esophagopleural fistula opening $2 \mathrm{~cm}$ above the esophagogastric junction (white arrow) prior to initializing the suturing procedure. Note retained sutures from a previous suturing attempt.

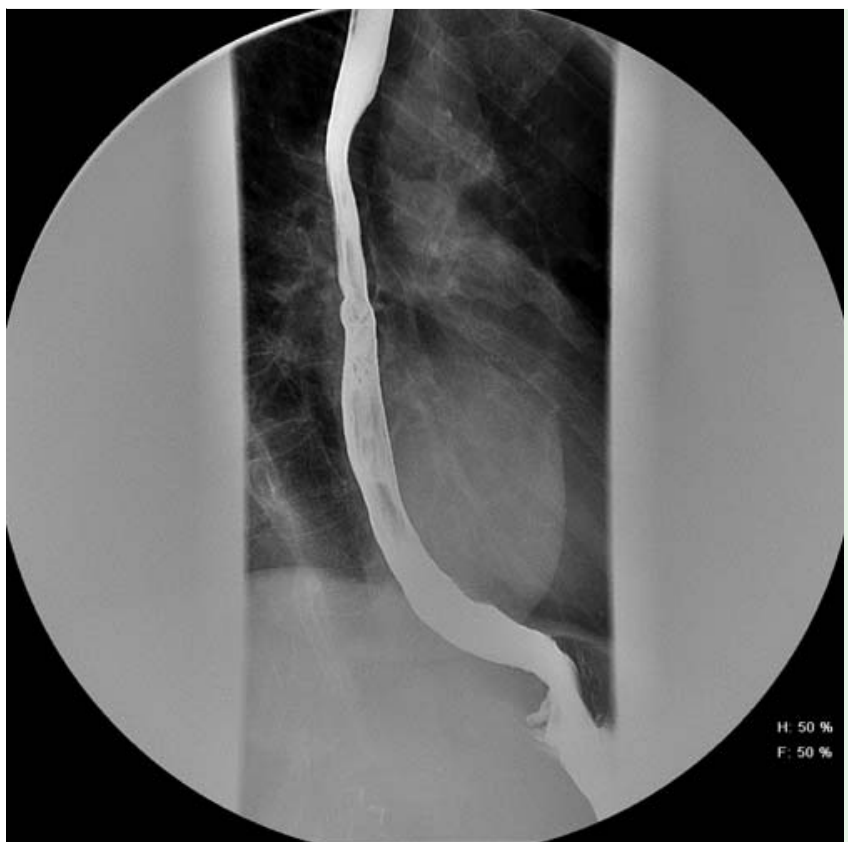

Fig. 5 Post-suturing contrast examination of the esophagus showing no contrast extravasation 2 months after the procedure; lateral view. A stent-induced esophageal stricture is seen in the mid esophagus.

previously. There was no contrast extravasation post suturing, and it was elected not to place a stent. The total procedure time was 90 minutes (20 minutes for the actual suturing procedure).

Follow-up endoscopy and contrast examination of the esophagus after the second suturing procedure showed complete fistula closure ( $\bullet$ Fig. 4 and $\bullet$ Fig.5).

\section{Video 1}

The technique for endoluminal esophagopleural fistula closure using a novel endoscopic suturing system.
Endoscopy_UCTN_Code_TTT_1AO_2AI

Competing interests: Dr. Gostout is a member of the Apollo group which conceptualized the suturing system. Dr. Gostout is an advisor to Apollo Endosurgery. Both he and the Mayo Clinic hold equity in this company. Drs. Louis Wong Kee Song, Juliane Bingener and Eduardo A. Bonin have nothing to disclose. Zachary Gostout was a former employee of Apollo Endosurgery, Inc., developer of the OverStitch device.

\section{E. A. Bonin ${ }^{1}$, L. M. Wong Kee Song ${ }^{2}$, Z. S. Gostout ${ }^{3}$, J. Bingener ${ }^{4,5}$, C. J. Gostout ${ }^{1}$}

${ }^{1}$ Developmental Endoscopy Unit, Mayo Clinic, Rochester, Minnesota, USA

${ }^{2}$ Department of Gastroenterology and Hepatology, Mayo Clinic, Rochester, Minnesota, USA

${ }^{3}$ Apollo Endosurgery, Inc

${ }^{4}$ Department of Surgery, Mayo Clinic, Rochester, Minnesota, USA

${ }^{5}$ Mayo Clinic and Foundation, Mayo Clinic, Rochester, Minnesota, USA

\section{References}

1 Raju GS. Endoscopic closure of gastrointestinal leaks. Am J Gastroenterol 2009; 104: $1315-1320$

2 Manta R, Manno M, Bertani $H$ et al. Endoscopic treatment of gastrointestinal fistulas using an over-the-scope clip (OTSC) device: case series from a tertiary referral center. Endoscopy 2011; 43: 545-548

3 Hampe J, Schniewind B, Both $M$ et al. Use of a NOTES closure device for full-thickness suturing of a postoperative anastomotic esophageal leakage. Endoscopy 2010; 42: 595-598

4 Moran EA, Gostout CJ, Bingener J. Preliminary performance of a flexible cap and catheterbased endoscopic suturing system. Gastrointest Endosc 2009; 69: 1375 - 1383

5 Kantsevoy SV, Thuluvath PJ. Successful closure of a chronic refractory gastrocutaneous fistula with a new endoscopic suturing device (with video). Gastrointest Endosc 2011: Epub

\section{Bibliography}

Dol http://dx.doi.org/

10.1055/s-0031-1291494

Endoscopy 2012; 44: E8-E9

(C) Georg Thieme Verlag KG

Stuttgart · New York

ISSN 0013-726X

Corresponding author

\section{J. Gostout, MD}

Developmental Endoscopy Unit

Mayo Clinic

200 First Street SW

Rochester

MN 55905

USA

Fax: +1-507-266-3939

gostout.christopher@mayo.edu 